Estudios Constitucionales, Año 17, № 1, 2019, pp. 151-188

ISSN 07180195

Centro de Estudios Constitucionales de Chile Universidad de Talca

"La participación en los beneficios para los pueblos indígenas,

recursos naturales y consentimiento previo, libre e informado"

María Gabriela Barros Sepúlveda

\title{
LA PARTICIPACIÓN EN LOS BENEFICIOS PARA LOS PUEBLOS INDÍGENAS, RECURSOS NATURALES Y CONSENTIMIENTO PREVIO, LIBRE E INFORMADO*
}

\section{BENEFIT-SHARING OF INDIGENOUS NATURAL RESOURCES AND PRIOR, FREE AND INFORMED CONSENT}

\author{
María Gabriela Barros Sepúlveda* \\ Pontificia Universidad Católica de Valparaíso \\ gabriela.barros@pucv.cl
}

RESUMEN: El presente artículo tiene por objeto determinar el contenido y fundamento del derecho a participar en los beneficios en proyectos de extracción o exploración de recursos naturales por los pueblos indigenas en el derecho internacional de los derechos humanos a partir del Convenio $N^{o} 169$ $y$ otras fuentes de derecho internacional que sirven para interpretar e integrar su sentido, a partir de la indisoluble relación entre el derecho en estudio y el derecho a los recursos naturales, y el consentimiento previo, libre e informado.

ABSTRACT: This paper aims to determine the content and justification of the benefit-sharing for indigenous people in extraction and exploitation of natural resources projects, according to the ILO Convention ( $\left.N^{\circ} 169\right)$ and other norms of international human rights, recognizing the essential link between the benefit-sharing, the natural resources management and prior, free and informed Consent.

PALABRAS CLAVE: derecho a participar en los beneficios, consulta indígena, recursos naturales, derechos indigenas - empresas y derechos humanos.

KEY WORDS: Benefit-sharing, consult, natural resources, the right to consultation, indigenous rights, business and human rights.

\section{INTRODUCCIÓN}

El presente artículo pretende determinar y sistematizar el contenido, contornos y fundamentos del derecho a participar en los beneficios para los pueblos indígenas, o benefit-sharing en inglés, en el contexto de proyectos de inversión, a partir de los instrumentos internacionales que lo consagran y la doctrina autorizada que lo ha estudiado.

\footnotetext{
* Artículo recibido el 10 de mayo de 2018 y aprobado el 10 de abril de 2019.

** Abogada. Licenciada en Ciencias Jurídicas y Sociales de la Pontificia Universidad Católica de Valparaíso. Profesora agregada en el Departamento de Derecho Público de la misma universidad.
} 
Establecido el objetivo, es necesario destacar que este derecho ha sido ampliamente desarrollado en el derecho internacional de la biodiversidad, sin embargo, no se puede afirmar lo mismo en el derecho internacional de los derechos humanos, en el cual solo existen referencias generales. Debido a ello, será necesario echar mano a los instrumentos internacionales del derecho internacional de la biodiversidad para estructurar y dar contenido a este derecho.

En atención a que la participación en los beneficios se encuentra ineludiblemente unida al derecho a la tierra, a la consulta y al derecho sobre los recursos naturales que se encuentran en las tierras de las comunidades indígenas o que de alguna forma ocupan es que será necesario analizarlos para comprender su contenido.

Respecto a sus modalidades de satisfacción, estas se han traducido en la forma de acuerdos, ya sea entre los Estados y los pueblos indígenas, ya sea entre empresas y pueblos indígenas. Es por ello que analizaremos la garantía del consentimiento previo, libre e informado, ya que esta juega un rol fundamental en la celebración de dichos convenios.

Cabe recalcar que los Estados son los destinatarios del deber de satisfacer el derecho a la participación en los beneficios para los pueblos indígenas en proyectos de extracción a partir de lo preceptuado en el Convenio No 169 de la Organización Internacional del Trabajo (en adelante, el Convenio No 169). A pesar de lo señalado, las empresas han comenzado a acordar ciertas condiciones, o celebrar acuerdos con comunidades indígenas, donde se otorgan una serie de beneficios a comunidades indígenas. En estos casos, estos deberán respetar los principios rectores entre empresas y derechos humanos, jugando un papel fundamental la debida diligencia en derechos humanos y la buena fe, así como otras normas no imperativas a las que haremos alusión.

\section{EL DERECHO A COMPARTIR BENEFICIOS PARA LOS PUEBLOS INDÍGENAS EN PROYECTOS DE INVERSIÓN: SU CONTENIDO Y FUNDAMENTO}

\section{IDEAS PRELIMINARES}

Para comenzar el análisis de la participación en los beneficios o el derecho a compartir beneficios de los pueblos indígenas en proyectos de inversión o extracción de recursos naturales es necesario primeramente aclarar algunos puntos.

En primer lugar, ni el derecho internacional público en general ni el derecho internacional de los derechos humanos en particular han provisto un concepto o la forma en que se debe entender este derecho. La problemática viene dada porque este aparece en variados ámbitos del derecho internacional, como son los 
relacionados con el derecho a la ciencia, el uso del conocimiento tradicional y los recursos genéticos, en el derecho internacional del mar, entre otros ${ }^{1}$. La doctrina comparada ${ }^{2}$, representada por Elisa Morgera, ha hecho el esfuerzo por estructurar y dotar de contenido este derecho, en atención a la pluralidad de ámbitos del derecho internacional público en que el emerge. No obstante dichos campos, en este artículo nos referiremos a la participación en los beneficios en proyectos de inversión, cuando consistan en la exploración o extracción de recursos naturales que pertenezcan al Estado, en tierras de los pueblos indígenas.

En segundo lugar, la participación en los beneficios se encuentra consagrada en el artículo 15.2 del Convenio No 169 y en el artículo 32 de la Declaración de las Naciones Unidas sobre los derechos de los pueblos indígenas. Es importante determinar el contenido a partir del artículo del Convenio, puesto que se discute la obligatoriedad que tiene la Declaración respecto de los Estados 3 , aun cuando esta última provea de criterios interpretativos relevantes.

En tercer lugar, cabe precisar que esta investigación tomará como base el artículo 15 del Convenio, pues este texto es el que regula los derechos de los pueblos indígenas de manera sistematizada y con carácter indiscutidamente obligatorio para los Estados que lo han ratificado, y además porque la participación en los beneficios se encuentra íntimamente ligada al derecho a la tierra, los recursos naturales y a la consulta, reconocidos en el Convenio.

Para su interpretación se utilizarán los criterios desarrollados en el derecho internacional de la biodiversidad, los que ya han sido considerados por la Corte IDH en el caso Pueblos Kaliña y Lokono vs. Surinam ${ }^{4}$. Esto sucede porque la regulación del artículo 15 es brevísima y deja variadas cuestiones sin resolver. Ante esto, como lo ha sostenido Morgera ${ }^{5}$, es posible un "intercambio de ideas" entre el derecho internacional de los derechos humanos y el derecho internacional de la biodiversidad para proveer de contenido al derecho en estudio.

Finalmente, es fundamental tener en cuenta que la participación en los beneficios se ha desarrollado en el contexto del llamado derecho al consentimiento previo,

1 Morgera (2016a), p. 354.

2 Morgera (2016a), pp. 353-383; Morgera (2016b), pp. 2-44.

3 Zalaquett (2008), p. 3.

4 Corte Interamericana de Derechos Humanos, Caso Kaliña y Lokono vs. Surinam, de 25 de noviembre de 2015.

5 Morgera (2016b), p. 2. 
libre e informado, cuyo sentido y alcance suele ser discutido. Este constituye un estándar más alto y diverso que el derecho a la consulta y en él se ha posibilitado la implementación del derecho a la participación en los beneficios a través de acuerdos.

\section{EL DERECHO A COMPARTIR BENEFICIOS EN EL}

\section{DERECHO INTERNACIONAL}

La participación en los beneficios es un concepto vago e impreciso, que no ha recibido toda la atención que merece, a la hora de determinar su real sentido y alcance. La tarea se vuelve compleja al apreciar que ha sido denominado de diversas formas, tales como: salvaguarda, mecanismo o derecho, $y$, a la vez, ha sido utilizado en diferentes ámbitos del derecho internacional, como son el derecho al desarrollo sostenible, el derecho a la ciencia y la justicia ambiental ${ }^{6}$.

Es necesario precisar que la participación en los beneficios supone una relación entre dos sujetos, uno que participa y otro que es beneficiario, pudiéndose dar las siguientes relaciones: entre Estados; dentro de un mismo Estado, entre él y las comunidades ${ }^{7}$, o entre las empresas y las comunidades, caso en el cual jugará un papel fundamental la responsabilidad de prevenir vulneraciones a los derechos humanos y respetarlos. En el presente artículo nos referiremos a los dos últimos casos.

En razón de esto es que analizaremos de modo conciso el Convenio de Diversidad Biológica (en adelante, CBD), ya que su regulación y lo que la Conferencia de los Estados ha acordado puede ser de importancia para delinear el derecho a compartir los beneficios en proyectos de explotación o exploración de recursos naturales que afecten a pueblos indígenas.

\section{El DERECHO A PARTICIPAR EN LOS BENEFICIOS DE LOS PUEBLOS INDÍGENAS RESPECTO DE LOS RECURSOS GENÉTICOS}

La consagración del derecho a participar en los beneficios en el ámbito del derecho internacional de la biodiversidad tuvo por objeto evitar injusticias y se debió a una cuestión meramente práctica, ya que con anterioridad a la vigencia del CBD,

6 Morgera (2016a), pp. 353-355. Según la misma autora, este concepto apareció por primera vez en el derecho internacional en la Declaración Universal de Derechos Humanos, en su artículo 27 [MorgerA (2015), p. 804].

7 Morgera (2016), p. 355. 
existían Estados desarrollados que extraían recursos genéticos de los territorios de Estados en vías de desarrollo, sin compartir los beneficios que les reportaba la comercialización del producto creado a partir del uso de dichos recursos ${ }^{8}$.

Antes de la entrada en vigor de dicho tratado, los recursos genéticos pertenecían a la humanidad toda, y actualmente, por efecto del CBD, pertenecen al Estado que sea soberano en el territorio en que se hallen ${ }^{9}$. Esto es lo que explica la instauración de la justa y equitativa participación en los beneficios entre Estados soberanos.

En este contexto, se buscaba que los beneficios o ganancias que generara la utilización de los recursos genéticos permaneciesen en el territorio del cual se habían extraído, lo que queda manifestado en los objetivos que precisamente indica el CBD en su artículo $1^{10}$, entre los que se encuentran la conservación de la diversidad biológica, la utilización sostenible de sus componentes, y la participación justa y equitativa de los beneficios que se deriven de la utilización de los recursos genéticos.

La justificación de compartir los beneficios de acuerdo a Schroeder radica en que, sin ello, podría existir el riesgo de su no conservación y uso sustentable, a partir de una perspectiva de beneficios mutuos, en que la ventaja para una parte es el acceso a los recursos genéticos no humanos y para la otra existirán beneficios, sean apreciables o no, en dinero ${ }^{11}$.

Ahora bien, en lo que respecta a los pueblos indígenas -y por ello, este tratado es sumamente relevante para luego interpretar el tenor del artículo del Convenio No 169 de la Organización Internacional del Trabajo-, el artículo $8^{\circ}$ j) del CBD establece que cada Estado, en la medida de lo posible y según proceda:

"Con arreglo a su legislación nacional, respetará, preservará y mantendrá los conocimientos, las innovaciones y las prácticas de las comunidades indígenas y locales ${ }^{12}$ que

8 SCHROEder (2009), p. 22.

9 Schroeder (2009), pp. 13 y 20.

10 "Los objetivos del presente Convenio, que se han de perseguir de conformidad con sus disposiciones pertinentes, son la conservación de la diversidad biológica, la utilización sostenible de sus componentes y la participación justa y equitativa en los beneficios que se deriven de la utilización de los recursos genéticos, mediante, entre otras cosas, un acceso adecuado a esos recursos y una transferencia apropiada de las tecnologías pertinentes, teniendo en cuenta todos los derechos sobre esos recursos y a esas tecnologías, así como mediante una financiación apropiada”.

11 Schroeder (2007), p. 207.

12 Cabe destacar que el Convenio sobre Diversidad Biológica establece como titulares del derecho no solo a las comunidades indígenas, sino también a las comunidades locales. Esto es así también para el consentimiento libre, previo e informado. 
entrañen estilos tradicionales de vida pertinentes para la conservación y la utilización sostenible de la diversidad biológica y promoverá su aplicación más amplia, con la aprobación y la participación de quienes posean esos conocimientos, innovaciones y prácticas, y fomentará que los beneficios derivados de la utilización de esos conocimientos, innovaciones y prácticas se compartan equitativamente".

Es decir, este convenio pone especial énfasis en el conocimiento tradicional que tienen los pueblos indígenas respecto de los recursos genéticos que utilizan, como por ejemplo el conocimiento de las propiedades de una planta que anula el apetito ${ }^{13}$. Este conocimiento tradicional lo han mantenido de generación en generación y es de utilidad para la humanidad toda. En esta línea, el uso de dicho conocimiento deberá necesariamente tener como contrapartida que los beneficios que de él se deriven se compartan entre quienes acceden a él y quienes permiten su acceso, que en este caso son los pueblos indígenas.

Para implementar la justa y equitativa participación en los beneficios o benefitsharing, se dictó el Protocolo de Nagoya, que en su artículo $5^{\circ}$ número 2 señala:

"Cada Parte adoptará medidas legislativas, administrativas o de política, según proceda, con miras a asegurar que los beneficios que se deriven de la utilización de recursos genéticos que están en posesión de comunidades indígenas y locales, de conformidad con las leyes nacionales respecto a los derechos establecidos de dichas comunidades indígenas y locales sobre estos recursos genéticos, se compartan de manera justa y equitativa con las comunidades en cuestión, sobre la base de condiciones mutuamente acordadas".

De la lectura del artículo podemos extraer que este establece una obligación para el Estado de legislar, dictar normas administrativas y crear políticas públicas en orden a posibilitar que exista una participación en los beneficios para con las comunidades indígenas, respetando sus leyes consuetudinarias. Para lograr la implementación de este derecho, desarrollado en el Protocolo, es que la Conferencia de las Partes, órgano decisor del CBD, acordó las Directrices de Bonn, que tienen por objeto socorrer a los Estados en la tarea de implementar el derecho a la justa y equitativa participación en los beneficios.

Además de las directrices voluntarias antes mencionadas, encontramos los lineamientos voluntarios Mo'otz Kuxtal, relacionados con el consentimiento previo, libre e informado que debe existir para acceder al conocimiento tradicional. Dichas guías o directrices son voluntarias, es decir, constituyen consejos para los

13 Schroeder (2007), p. 205. 
Estados-parte, y pueden ser de gran ayuda para estructurar una de las formas de satisfacción de la participación en los beneficios, como son los acuerdos de acceso a los recursos naturales en tierras indígenas.

Habiendo revisado brevemente los objetivos de aquel convenio, es necesario destacar que el fundamento que se ha esgrimido para compartir los beneficios con los pueblos indígenas en este ámbito es que ellos han posibilitado la mantención y el cuidado del conocimiento tradicional, desarrollando métodos para el manejo y tratamiento de los recursos genéticos ${ }^{14}$. Lo anterior, en nuestra opinión, diverge del fundamento que tiene el derecho a participar en los beneficios en proyectos de extracción de recursos naturales que pertenezcan al Estado, para los pueblos indígenas, en virtud del Convenio No 169 de la OIT.

\section{El DERECHO A PARTICIPAR EN LOS BENEFICIOS EN EL Convenio No 169 de LA OIT}

En América Latina, los pueblos indígenas han vivido procesos de marginalización en variados ámbitos y suelen vivir en condiciones de pobreza ${ }^{15}$. Es en este contexto que desde la década de los 80 han existido movimientos para abogar por el reconocimiento de derechos de los pueblos indígenas ${ }^{16}$, lo que explica el nacimiento de diversos instrumentos que han tenido como objetivo aquello ${ }^{17}$. Sin embargo, no solo se ha buscado consagrar derechos en su favor, sino también propender a la reparación de las vulneraciones de derechos humanos que han experimentado a lo largo de la historia. El punto culminante de este reconocimiento se encuentra representado por el Convenio No 169, que consagró distintos derechos de los pueblos indígenas en un mismo cuerpo normativo; derechos tales como la autodeterminación, la consulta, y los derechos territoriales y a los recursos naturales de los pueblos indígenas.

En el sistema interamericano de derechos, la Corte Interamericana de Derechos Humanos (en adelante, Corte IDH) ha desarrollado el "derecho a participar en los beneficios" o "beneficios compartidos" a partir de dos fallos principalmente ${ }^{18}$ :

14 Morgera (2016b), p. 19.

15 Almut-Schilling y Flemmer (2013), p. 10.

16 Hanna y Vanclay (2013), p. 148.

17 Hanna y Vanclay (2013), p. 148.

18 En Pueblo Kichwa de Sarayaku vs. Ecuador (2012), la corte no se refirió a lo que ella llama "beneficios compartidos", por falta de prueba (párr. 156). En el caso Comunidad Garífuna de Punta Piedra y sus miembros vs. Honduras (2015), solo los nombra, sin referirse con profundidad a estos (párr. 215). 
Pueblo Saramaka vs. Surinam (2008) ${ }^{19}$, y Pueblo Kaliña y Lokono vs. Surinam (2015). Ambos tienen en común que los pueblos indígenas han visto afectados sus derechos a la tierra, territorio y recursos naturales por los impactos que traen consigo proyectos de inversión o extracción.

La Corte IDH ha desarrollado determinados lineamientos que deben ser considerados por los Estados-parte de la Convención al momento de decidir iniciar o autorizar un proyecto de inversión que suponga exploración o extracción de recursos naturales de toda índole que se encuentren dentro de tierra o territorio indígena, aun cuando no exista un título de propiedad sobre ellos; dichas directrices son tres: a) cumplir con el derecho internacional sobre expropiación, b) que no se trate de proyectos que amenacen la supervivencia del pueblo indígena, c) y que los beneficios que reporte la actividad sean compartidos con las comunidades indígenas y que también, previo a ello, exista un estudio de impacto ambiental ${ }^{20}$.

Ahora bien, el último de los requisitos corresponde al derecho en estudio, el que, a la vez, debe cumplir con ciertas salvaguardas, que son: la participación de los pueblos indígenas a través de la consulta, la existencia de un estudio de impacto social y ambiental, y los beneficios compartidos ${ }^{21}$. Ha desarrollado su razonamiento fundamentándolo especialmente en el artículo 21.2 de la Convención Americana, puesto que sería inherente al derecho a una indemnización justa y equitativa ${ }^{22}$.

Ahora bien, en este artículo tomaremos como base de análisis el enunciado normativo contenido en el artículo 15 del Convenio, lo que no implica desconocer el valor de la jurisprudencia de la Corte IDH. Al revisar el texto de la disposición del tratado, es posible vislumbrar que es bastante conciso; preceptúa:

1. Los derechos de los pueblos interesados a los recursos naturales existentes en sus tierras deberán protegerse especialmente. Estos derechos comprenden el derecho de esos pueblos a participar en la utilización, administración y conservación de dichos recursos.

19 Corte Interamericana de Derechos Humanos, Caso del Pueblo Saramaka vs. Surinam, de 12 de agosto de 2008.

20 Corte Interamericana de Derechos Humanos, Caso Pueblos Kaliña y Lokono vs. Surinam, de 25 de noviembre de 2015, pp. 57-64.

21 Corte Interamericana de Derechos Humanos, Caso del Pueblo Saramaka vs. Surinam, de 12 de agosto de 2008; Corte Interamericana de Derechos Humanos, Caso Pueblo Kichwa de Sarayaku vs. Ecuador, de 27 de junio de 2012; Corte Interamericana de Derechos Humanos, Caso Pueblos Kaliña y Lokono vs. Surinam, de 25 de noviembre de 2015.

22 Comisión Interamericana de Derechos Humanos (2010), p. 100. 
2. En caso de que pertenezca al Estado la propiedad de los minerales o de los recursos del subsuelo, o tenga derechos sobre otros recursos existentes en las tierras, los gobiernos deberán establecer o mantener procedimientos con miras a consultar a los pueblos interesados, a fin de determinar si los intereses de esos pueblos serían perjudicados, y en qué medida, antes de emprender o autorizar cualquier programa de prospección o explotación de los recursos existentes en sus tierras. Los pueblos interesados deberán participar siempre que sea posible en los beneficios que reporten tales actividades, y percibir una indemnización equitativa por cualquier daño que puedan sufrir como resultado de esas actividades.

En el número 1, se establece el derecho a los recursos naturales, lo que supone el derecho a participar en su utilización, administración y conservación de dichos recursos, es decir, podrían existir formas de compartir los beneficios en este ámbito, lo cual no será tratado especialmente en este trabajo, ya que nos centraremos en artículo 15.2, en el que se establecen los elementos que deben concurrir para que la participación en los beneficios sea posible:

a) Se trate de recursos mineros, del subsuelo u otros que pertenezcan al Estado y que se encuentren en tierras de los pueblos indígenas.

b) La propiedad de estos recursos haya sido retenida por el Estado.

c) El Estado respectivo, para comenzar o autorizar un programa de prospección o explotación de dichos recursos, deberá consultar a los pueblos para determinar si sus intereses resultarían perjudicados.

Por lo tanto, existe una sutil diferencia entre el derecho a los recursos naturales consagrado en el número 1 y el supuesto establecido en el número 2, ya que en el primero se engloba la gran mayoría de los recursos que se encuentran en las tierras o territorios que los pueblos indígenas ocupan, por lo que el derecho de propiedad sobre las tierras abarcaría el de los recursos naturales ${ }^{23}$. Por otro lado, en el número 2, el supuesto consagrado en este es más específico, puesto que se refiere a recursos naturales en particular, cuya propiedad corresponde al Estado, y aun cuando le pertenezcan, debe cumplir con diversas salvaguardas para su extracción, como son la consulta especial, la participación en los beneficios, si es ello posible, e indemnizar los daños, en caso de producirlos.

Ahora bien, antes de comenzar propiamente el análisis del derecho objeto de estudio, debemos tener en cuenta diversos conceptos para poder comprender el

23 Comisión Interamericana de Derechos Humanos (2010), p. 78. 
contenido y contornos del derecho a participar en los beneficios. Estos conceptos son: el derecho a la tierra, el derecho a los recursos naturales y el derecho a la consulta previa, los cuales se extraen del propio artículo 15.2 del Convenio No $169^{24}$, como presupuestos necesarios y básicos del derecho a participar en los beneficios en sentido estricto.

\section{a) Derecho a la tierra}

En materia indígena, desde una perspectiva antropológica, tierra y territorio no son conceptos sinónimos, ya que la noción de territorio es más amplia, siendo este último la apropiación del espacio -tanto material como simbólica-, y en él se incluyen diversos elementos como son la tierra, los recursos naturales, la historia y la cosmovisión, entre otros. Asimismo, el territorio goza de una dimensión material y otra simbólica ${ }^{25}$. La primera se refleja mediante la tenencia, uso, control y dominio de fracciones de espacio ${ }^{26}$, esto es, en una palabra: la tierra, y la segunda "va más allá de la tierra", constituida "por ejemplo a través de las redes de parentesco, el sentido de pertenencia, la topofilia o apego al territorio, o los proyectos etno-políticos con base en el territorio ${ }^{27}$ ". Esta última es la dimensión que se reconoce en el derecho internacional al recoger la noción de territorio ${ }^{28}$.

A diferencia de la tierra, la noción de territorio presenta ciertas particularidades que la dotan de una complejidad mayor, por cuanto en él confluyen factores sociales, culturales y políticos. Este incluye "todo cuanto pertenece a las propias tierras, como son las aguas, el subsuelo, el espacio aéreo, todos sus ocupantes, toda la vida vegetal y animal y todos los recursos" 29 .

El Convenio realiza esta distinción en su artículo 13.2, al referir que "La utilización del término 'tierras' en los artículos 15 y 16 deberá incluir el concepto de territorios, lo que cubre la totalidad del hábitat de las regiones que los pueblos interesados ocupan o utilizan de alguna otra manera”. Así, el Convenio, para efec-

${ }_{24}$ De acuerdo a Donoso, Sebastián (2014), es necesario tener en cuenta el triángulo territorio, consulta y participación en los beneficios [Donoso (2014), p. 10].

25 Bello (2011), pp. 44-47; Bello (2004), pp. 104-105.

26 Bello (2011), p. 46.

27 Bello (2011), p. 42.

28 Bello (2011), p. 58.

29 Aguilar (2007), p. 524. En el mismo sentido, Corte IDH, Caso del Pueblo Saramaka vs. Surinam, 28 de noviembre de 2007. 
tos del artículo 15, parece hacerlos sinónimos. Ante esta situación, es necesario recalcar que el concepto de tierra, según el artículo 15, es uno de carácter amplio.

\section{b) Derecho de los pueblos indigenas a los recursos naturales}

El artículo 15.1 del Convenio No 169, como ya mencionamos, consagra el derecho de los pueblos indígenas sobre los recursos naturales, los que forman parte del territorio en su dimensión simbólica. Según Aguilar y Alfaro, esta norma incluye "una importante norma medioambiental, reconociendo el derecho de los pueblos indígenas a participar en la conservación de los recursos naturales existentes en sus tierras" 30 . No obstante, desde nuestro punto de vista, el derecho no se agota solo en la conservación de los recursos, sino que incluye su utilización y administración.

Existe una relación o vínculo especial de carácter holístico ${ }^{31}$ entre los pueblos indígenas y los recursos naturales existentes en sus tierras o territorios; esta relación explicaría la especial protección que reclama el derecho a los recursos naturales por parte de los pueblos indígenas. De acuerdo con Aguilar, existe un derecho de los pueblos indígenas a la soberanía permanente sobre sus recursos naturales ${ }^{32}$. Este mismo autor afirma, citando al relator especial Stavenhagen, que no puede desvincularse el acceso a los recursos naturales del derecho a la tierra, puesto que estos son fundamentales para su desarrollo económico y social ${ }^{33}$, entendiendo de esta forma que el control de los recursos naturales "forma parte necesaria del goce cabal del derecho básico a la autodeterminación de los pueblos indígenas" 34 .

Meza afirma que sobre los recursos naturales existiría propiedad ${ }^{35}$; sin embargo, creemos que es necesario distinguir si se tratan o no de los tipos de recursos especificados en el artículo 15.2, según ya analizamos. Es por esta razón que sostenemos que el Convenio pone especial cuidado, más bien, en el control sobre los recursos naturales que se encuentren en las tierras que los pueblos indígenas ocupan de alguna manera, puesto que en la reunión de la Conferencia Interna-

\footnotetext{
30 Aguilar y Alfaro (2015), p. 185.

31 Agullar (2007), p. 527.

32 Agullar (2007), p. 562.

33 Agullar (2007), p. 558.

34 Aguilar (2007), p. 558.

35 Meza (2014), p. 488.
} 
cional del Trabajo de 1988 se llegó a la conclusión de que debía posibilitarse el máximo control de los pueblos indígenas sobre su desarrollo social, económico y político ${ }^{36}$, existiendo "acuerdo general sobre la necesidad de establecer procedimientos para negociar las condiciones en que la explotación de estos recursos podría tener lugar" 37 .

Ahora bien, si los recursos naturales - del subsuelo, minerales u otros cuya propiedad pertenezca al Estado- se encuentran en las tierras de los pueblos indígenas, el artículo 15.2 obliga a consultar y compartir los beneficios de dicha explotación o exploración.

\section{c) Derecho a la consulta previa}

El derecho a la consulta previa a los pueblos indígenas es un derecho que proviene de su derecho a la autodeterminación ${ }^{38}$ y "contribuye a la protección de la integridad cultural asegurando que los pueblos indígenas toman parte de la evaluación de las medidas con el potencial de impactar su relación con su tierra y los recursos naturales" 39 .

Existen diversas fuentes de donde surge el derecho a la consulta ${ }^{40}$; no obstante, aquella que es propiamente obligatoria para los Estados es el Convenio No 169 , ya que las otras se tratan más bien de normas de soft law $w^{41}$, como son la Declaración de las Naciones Unidas sobre los derechos de los pueblos indígenas y diversas directrices de organizaciones internacionales.

En el artículo $6^{\circ}$ del referido Convenio, se especifica que los Estados deberán consultar a los pueblos indígenas cada vez que existan medidas legislativas o administrativas que hayan de afectarles directamente. Se trata de una obligación estatal $^{42}$ que tiene por objeto obtener el consentimiento de los pueblos indígenas

36 Huaco (2015), p. 250.

37 HuACO (2015), p. 250.

38 Almut-Schilling y Flemer, (2013), p. 10.

39 Cabrera Ormaza (2017), p. 63. "Consultation contributes the protection of the cultural integrity of indigenous people by ensuring that these communities take part in assessing measures with the potential to impact their cultural relationship with their land and natural resources". Traducción propia.

40 Almut-Schilling y Flemer (2013), p. 13.

41 Almut-Schilling y Flemer (2013), p. 13.

42 Meza (2013), pp. 396 y 399. 
de buena fe, por el Estado, el cual es distinto del consentimiento previo, libre e informado, debido a que este último constituye un estándar más alto.

Según la Corte IDH, "el deber del Estado en relación con dicha garantía se actualiza de manera previa a la ejecución de acciones que podrían afectar de manera relevante los intereses de los pueblos indígenas y tribales, tales como las etapas de exploración y explotación o extracción de recursos naturales en sus tierras” 43 . El mismo tribunal ha establecido que, cuando se trate de proyectos de inversión a gran escala y que, por lo tanto, potencialmente tendrán un impacto mayor para el pueblo indígena respectivo, el Estado no solo debe consultar, sino que debe conseguir el consentimiento libre, previo e informado ${ }^{44}$.

Ahora bien, en el artículo 15.2 del Convenio se hace alusión a la consulta en términos distintos que los del artículo 6 del mismo tratado -la que podemos entender como consulta general ${ }^{45}$-, ya que el artículo 15.2 se refiere al supuesto de que, con anterioridad a comenzar o autorizar proyectos de prospección o explotación de los recursos naturales que existan en las tierras de las comunidades indígenas (del subsuelo, mineros u otros), se deberá consultar para "determinar si los intereses de esos pueblos serían perjudicados, y en qué medida”, según señala aquel artículo.

Es decir, a través de la consulta consagrada en el artículo 15.2 se trata de establecer el grado de afectación de los intereses de los pueblos indígenas, no siendo necesaria una determinación previa de los impactos que la medida pueda producir. En otras palabras, no es imperativo determinar la existencia de "susceptibilidad de afectación directa" 46 : se trataría de una consulta que tiene primordialmente un carácter preventivo ${ }^{47}$ y que se efectúa para especificar "el grado en que los intereses de los pueblos indígenas serian afectados por programas de exploración o explotación de recursos naturales" ${ }^{48}$. Así, según Carmona, es posible sostener que existe una regla objetiva en el artículo 15.2 consistente en que los recursos

43 Corte Interamericana de Derechos Humanos, Caso Pueblos Kaliña y Lokono vs. Surinam, de 25 de noviembre de 2015 .

44 Corte Interamericana de Derechos Humanos, Caso Pueblo Saramaka vs. Surinam, de 12 de agosto de 2008 .

45 Carmona (2015), p. 11.

46 Carmona (2015), p. 11; Carmona y Schönsteiner (2018), p. 11.

47 Cabrera Ormaza (2017), p. 63.

48 Cabrera Ormaza (2017), p. 63. "To determine to what degree the interests would be affected by programmes for the exploration and exploitation of resources located within their lands". 
naturales se encuentren en tierras indígenas, entendiendo por tierras el concepto del artículo 13.2 del Convenio. Por lo tanto, basta con que los recursos cuya autorización de extracción se busca se encuentren en tierras que los pueblos indígenas ocupen de alguna manera ${ }^{49}$.

Respecto al derecho en análisis, la consulta es ineludible antes de proceder a la exploración o explotación de recursos naturales mediante proyectos de inversión, etapa en la cual los pueblos indígenas deben conocer tanto los impactos positivos como negativos del proyecto ${ }^{50}$, permitiendo que la consulta sea un espacio de efectivo diálogo y negociación ${ }^{51}$. A mayor abundamiento, en este contexto la consulta debe posibilitar que las comunidades indígenas ejerzan su derecho a la autodeterminación, fijando ellas mismas sus prioridades de desarrollo ${ }^{52}$, lo que está estrechamente relacionado con el fundamento de la participación en los beneficios.

Cabe agregar que al determinar cuáles los intereses de los pueblos indígenas resultaran afectados o perjudicados y cómo, deberán estudiarse medidas adecuadas de mitigación de los posibles riesgos que la actividad puede generar, ya sea por parte de la empresa o del Estado, en su calidad de sujeto supervisor del proceso de negociación. Estas medidas, su naturaleza y condiciones, debieran ser determinantes en orden a que el pueblo indígena respectivo preste su consentimiento.

\section{d) El derecho a participar en los beneficios en proyectos de extracción} de recursos naturales por los pueblos indigenas en sentido estricto

Como señalamos más arriba, el CBD reconoce el derecho a compartir los beneficios de manera justa y equitativa respecto de los recursos genéticos, y si bien el CBD no establece una relación entre compartir los beneficios y el uso de los recursos naturales tradicionalmente utilizados por los pueblos indígenas, Morgera entiende que es posible incluirlos, realizando una interpretación sistemática del $\mathrm{CBD}^{53}$, debido a que el CBD contempla que cada Estado-parte debe en la

49 Carmona y Schonsteiner (2018), p. 12.

50 Morgera (2016b), p. 33.

51 FAÚNDES (2013), p. 209.

52 ANAYA (2013), párr. 9.

53 Morgera (2016b), p. 16. 
medida de lo posible y según proceda alentar la participación en los beneficios de forma equitativa en el uso del conocimiento tradicional, y aun cuando el CBD no haga referencia a los recursos naturales y su relación con la participación en los beneficios, se puede sostener un vínculo entre la participación en los beneficios en el uso del conocimiento tradicional y la obligación de protección del uso consuetudinario sustentable de los recursos biológicos, incluyendo en estos a los recursos naturales vivos. Agrega además que "una interpretación sistemática del texto del CBD permite incluir bajo su ámbito de aplicación a recursos naturales no vivos, como minerales; por ser parte de los ecosistemas o bien, la extracción de recursos no vivos podría afectar la conservación de recursos vivos" 54 .

La idea clave en opinión de Morgera es la administración del ecosistema ${ }^{55}$, ya que, según expresa, para los pueblos indígenas la distinción entre administración del ecosistema y el conocimiento tradicional realmente no existe ${ }^{56}$. Sostiene que la razón de dicha interpretación es que, en la Conferencia de las Partes, si bien en principio existió un rechazo al uso de un discurso de derechos humanos, con el pasar del tiempo aquello cambió y ha comenzado a existir una significativa aclaración de los conceptos y la normativa ${ }^{57}$.

De esta forma, a partir de esta interpretación sistemática es posible ampliar la aplicación del CBD y los estándares desarrollados para él, al caso de explotación o exploración de recursos naturales en tierras de los pueblos indígenas. Empero, desde nuestro punto de vista, creemos que una mejor opción es analizar el derecho desde el Convenio No 169 de la OIT, el cual en su articulado consta de diversos principios que sirven para articular el contenido del derecho. Al mismo tiempo, sostenemos que la participación en los beneficios en el derecho de la biodiversidad tiene una justificación o fundamento distinto a la participación en los beneficios en el derecho internacional de los derechos humanos, específicamente en el Convenio No 169 , lo que no obsta a que los estándares desarrollados por la Conferencia de las Partes para el CBD puedan ser aplicados al Convenio.

\footnotetext{
54 Morgera (2016b), p. 16, “(...) systematic interpretation of the CBD text allows to include under its scope also non-living natural resources, such as minerals, either as part of ecosystems or in as far as extraction of nonliving resources may affect the conservation of living resources". Traducción propia.

55 Morgera (2016b), p. 16.

56 Morgera (2016b), p. 17.

57 Morgera (2015), p. 805; Morgera (2016b), p. 16; Corte Interamericana de Derechos Humanos, Caso Pueblos Kaliña y Lokono, de 25 de noviembre de 2015.
} 
Así, nos referiremos a la situación en que el propio Estado, o una empresa a partir de una autorización estatal, comienza un proyecto de inversión que consiste en la extracción o exploración de recursos naturales del subsuelo, cuando el Estado ha retenido la propiedad de estos. En este contexto, ¿cuál es el contenido del derecho a participar en los beneficios? ¿Cuáles son los elementos del mismo? ¿Por qué los pueblos indígenas tienen derecho a participar en los beneficios generados por esta actividad? ¿De qué tipo o naturaleza deben ser estos beneficios? ¿Este derecho se identifica con una indemnización? A estas interrogantes intentaremos dar respuesta en el desarrollo del presente artículo.

Ahora pasaremos a analizar su fundamento, el contenido del derecho y sus formas de satisfacción ${ }^{58}$.

\section{i. Fundamento}

En el fundamento del derecho en análisis confluyen diversos factores: uno de ellos, y que consideramos el más relevante, es el control de los recursos naturales por parte de los pueblos indígenas, entendiendo por este la posibilidad de determinar su uso y administración según sus propias prioridades ${ }^{59}$, lo que aplica tanto a los recursos naturales en general como a los considerados en el artículo 15.2 del Convenio No 169. Un segundo factor, que se encuentra íntimamente ligado al anterior, es el derecho a la autodeterminación de los pueblos indígenas, el cual va de la mano con el reconocimiento de su derecho a la tierra, a los recursos naturales y el derecho a mantener su integridad e identidad cultural.

De acuerdo a Aguilar, el derecho a la autodeterminación "implica necesariamente el control, desarrollo y utilización de sus recursos, aguas y zonas costeras y no constituye un privilegio para los pueblos indígenas" 60 . De este existen dos dimensiones: una externa y una interna; la primera se refiere a "un derecho a la secesión"61, y la segunda consiste en el disfrute de una autonomía limitada dentro del territorio del Estado, en orden a tener un gobierno sobre sí mismos y a participar en las decisiones que les afecten ${ }^{62}$. Es en este último modo como

58 Cabe destacar que el derecho a participar en los beneficios, con una estructura parecida a la del Convenio, se encuentra reconocido en el artículo 57 número 7 de la Constitución de Ecuador.

59 ANAYa (2013), párr. 9.

60 Aguilar (2007), p. 558.

61 LeNZERINI (2009), p. 99.

62 LenZerini (2009), pp. 99-100. 
comprendemos el derecho a la autodeterminación, puesto que los pueblos indígenas se encuentran "en el territorio de un Estado soberano e independiente"63.

En palabras del exrelator James Anaya, es manifiesto que la razón o justificación para que los pueblos indígenas se beneficien de los proyectos de extracción se debe a que aun cuando no sean considerados propietarios de los recursos naturales, al consentir en dichos proyectos "proporcionan acceso a los recursos y renuncian a otras opciones de desarrollo de sus territorios en el futuro"64.

En este orden de ideas, los pueblos indígenas pueden determinar sus propias prioridades de desarrollo ${ }^{65}$, es decir, las comunidades indígenas tienen derecho a la mantención de su subsistencia cultural frente a proyectos de extracción que imposibilitan su relación con los recursos naturales y sus tierras, y que incluso podrían afectar aspectos de su cosmovisión ${ }^{66}$.

Ahora bien, es crucial anotar que dichos proyectos deben efectuarse con pleno respeto de los derechos de los pueblos indígenas, y de otras comunidades, previos estudios de impacto ambiental y social, posibilitando un desarrollo sustentable de cada Estado; lo que se busca evitar es el fenómeno conocido como extractivismo. Entendemos por este último un "tipo de extracción de recursos naturales, en gran volumen o alta intensidad, y que están orientados esencialmente a ser exportados como materias primas sin procesar, o con un procesamiento mínimo"67; este es causado, según señala Aguilar, por el no reconocimiento de los derechos territoriales de los pueblos indígenas ${ }^{68}$. Es decir, debe existir una estructura jurídica en que el derecho al territorio, a los recursos naturales y a la consulta constituya un entramado que haga posible un ambiente adecuado para el ejercicio de la participación en los beneficios.

Es este sentido, la participación en los beneficios se encuentra estrechamente relacionada al consentimiento libre, previo e informado, ya que el pueblo indígena no puede verse amenazado o forzado a aceptar un proyecto que puede socavar o hacer desaparecer su identidad o integridad cultural.

63 Del Carpio (2011), p. 35

64 ANAYa (2013), párr. 76.

65 Anaya (2013), párr. 9.

66 Comisión Interamericana de Derechos Humanos (2009), pp. 21-22.

67 Gudynas (2013), p. 3.

68 Aguilar (2017), p. 19. 
La identidad cultural, de acuerdo a Del Carpio, se encuentra determinada por diversos factores, entre los que se halla el político, que supone la existencia de una cultura dominante y otra dominada ${ }^{69}$. En el caso de los pueblos indígenas, estos tienen una identidad cultural vinculada al territorio ${ }^{70}$, que, como ya hemos hecho referencia, es una noción en que confluyen diversos factores sociales, políticos y culturales, y que incluyen todo el hábitat que los pueblos ocupan o utilizan de alguna manera, de acuerdo al artículo 13.2 del Convenio No 169.

Es así como existen distintos elementos que confluyen en el fundamento de este derecho, pero creemos que la idea fundamental que subyace a él es que los beneficios directos constituyen una herramienta para balancear intereses en relaciones de poder esencialmente desiguales ${ }^{71}$, debido a que las comunidades indígenas son generalmente grupos humanos vulnerables y marginalizados dentro de una sociedad ${ }^{72}$. Por lo tanto, el reconocer este derecho sobre el control de los recursos naturales y autonomía para determinar sus prioridades de desarrollo (y que resguarda su integridad cultural y subsistencia), hace equilibrar la balanza y abre esferas de negociación.

\section{ii. Nomenclatura y contenido}

En la versión en inglés de los tratados internacionales donde se encuentra consagrada la participación en los beneficios se utiliza la denominación benefit-sharing, poniendo énfasis en "compartir los beneficios". No obstante ello, en el Convenio No 169 en su versión en inglés es utilizada la denominación participate in. Por sharing podemos comprender "la acción de dar una porción de algo a otro" 73 , y por benefit, "una ventaja o ganancia obtenida por algo" 74 . En el CBD se formula que esto debe ser "justo y equitativo", menciones que no se encuentran en el Convenio No 169, pero se ha entendido que debiese cumplir con aquellas cualidades ${ }^{75}$.

$\mathrm{Al}$ revisar la discusión que existió entre los Estados al momento de la revisión del Convenio No 107 , se puede constatar que el artículo que analizamos fue fruto del

69 Del Carpio (2011), pp. 25-26.

70 Del Carpio (2011), p. 35.

71 Morgera (2016), p. 355.

72 Altman (2009), p. 288.

73 Schroeder (2006), p. 205.

74 Schroeder (2006), p. 205.

75 Morgera (2016b), p. 20. 
deseo de hacer realidad el control de los recursos naturales por parte de los pueblos indígenas, sin perjuicio del fundamento antes explicado. Así, en el primer informe de la Oficina Internacional del Trabajo, se hace una referencia a Estados en que ha existido participación en los beneficios en proyectos de explotación de recursos naturales, entre los que se encontraban Panamá, Canadá y Australia ${ }^{76}$, especificando que “(...) [1] os ejemplos precedentes reflejan situaciones en las que se ha permitido a los pueblos indígenas y tribuales (sic) ejercer cierto control sobre el proceso de explotación de minerales y recursos naturales en sus tierras o intervenir en negociaciones sobre la participación en ganancias y beneficios. Sin embargo, incluso en estas situaciones ha habido quejas generalizadas por parte de los pueblos indígenas y tribales afectados con respecto a la insuficiencia de las disposiciones existentes sobre su protección y participación. Y en muchas partes del mundo, especialmente en lo que atañe a pueblos indígenas y tribuales (sic) silvícolas, no existen ni siquiera garantías mínimas en esta esfera. Como resultado, la puesta en práctica de proyectos de explotación minera, forestal, hidroeléctrica y de otra índole ha provocado a menudo el éxodo de estos pueblos fuera de su medio ambiente tradicional"77.

En dicho informe de la oficina, se incluía un cuestionario de preguntas para los Estados, cuyas respuestas dieron nacimiento al Informe VI (2). A partir de las respuestas transcritas, y de la discusión en la $75^{\circ}$ Conferencia, se redactó un proyecto de Convenio, el cual en su artículo $14.2^{78}$ contemplaba la participación en los beneficios con la siguiente redacción:

"Los gobiernos deberán recabar el consentimiento de los (pueblos/poblaciones) interesados, mediante mecanismos apropiados, antes de emprender o autorizar cualquier programa de prospección o explotación de recursos minerales y otros recursos del subsuelo existentes en sus territorios tradicionales. Deberá asegurarse una indemnización equitativa por cualquier actividad de esta indole realizada en el territorio de esos (pueblos/poblaciones)".

Si bien el artículo del proyecto establecía que los Estados debían buscar el consentimiento de los pueblos indígenas -lo que es más garantista en relación con

\footnotetext{
76 Conferencia Internacional del Trabajo (1988a), pp. 64 y 65.

77 Conferencia Internacional del Trabajo (1988a), p. 66.

78 El número 1 de este artículo señalaba: Deberán tomarse medidas especiales para salvaguardar el control por los (pueblos/poblaciones) interesados de los recursos naturales existentes en sus territorios tradicionales, incluidos la fauna y la flora, las aguas, los hielos marinos y otros recursos naturales de superficie [CONFERENCIA InTERnACiONAL Del Trabajo (1989a), p. 10].
} 
los estándares internacionales, constituyendo un estándar mayor que la consulta-, este establecía no una participación, sino una indemnización, lo que desnaturaliza el contenido del derecho analizado.

Cabe destacar que la discusión sobre el tema de las tierras se depuso para la $76^{\circ}$ Internacional del Trabajo - por su complejidad y falta de acuerdo-, por lo que este artículo se redactó en conformidad al Informe VI (2). En el transcurso de la revisión parcial del Convenio No 107, en el Informe IV 2A se analiza particularmente este derecho y se transcriben las observaciones específicas que realizaron los Estados a su redacción; entre los Estados que realizaron observaciones a la consagración del derecho a participar en los beneficios se encuentran Australia, Canadá, India y México.

En este contexto, Australia opinó que la expresión "indemnización equitativa” era muy amplia, por lo cual recomendó modificarla por "los pueblos interesados controlarán todo proceso de extracción de minerales y tendrán derecho a participar equitativamente en los beneficios obtenidos de toda extracción para la que hayan dado su consentimiento" 79 . Por su parte, Canadá declaró que debería reformularse la parte del derecho de los beneficios compartidos, quedando redactada como: "Deberá asegurarse una indemnización íntegra, basada en acuerdos negociados con los representantes de los pueblos interesados, por cualquier actividad de esta índole realizada en el territorio de esos pueblos" 80 . India estableció que en el párrafo dos debería incluirse las palabras "en la medida de lo posible" 81 . Por su parte, México especificó que los pueblos indígenas debían ser los beneficiarios directos de los proyectos de explotación.

A partir de las observaciones de los países, la oficina discurrió que el concepto de indemnización equitativa quedaba por definir por cada Estado y se modificó la redacción, quedando de la siguiente manera: "Los pueblos interesados deberán participar siempre que sea posible en los beneficios que reporten tales actividades, y percibir una indemnización equitativa por cualquier actividad de esta índole realizada en sus territorios" 82 . Esta redacción se mantuvo hasta convertirse en el

\footnotetext{
79 Conferencia Internacional del Trabajo (1989a), p. 40.

80 Conferencia Internacional del Trabajo (1989a), p. 40.

81 Conferencia Internacional del Trabajo (1989a), p. 42.

82 En la comisión se incluyeron al principio del artículo 15.2 las oraciones "En caso de que pertenezca al Estado la propiedad de los minerales o de los recursos del subsuelo, o tenga derechos sobre otros recursos existentes en las tierras, los gobiernos deberán establecer o mantener procedimientos con miras a consultar a los pueblos interesados, a fin de determinar si y en qué medida los intereses de esos pueblos serían perjudicados,
} 
Convenio No 169; no obstante, hubo variadas modificaciones del artículo 15 por la Oficina Internacional ${ }^{83}$, y luego por la Comisión ${ }^{84}$.

A partir de la revisión de la discusión que preexistió al texto del Convenio, se puede llegar a diversas conclusiones: en el transcurso de las opiniones no parece existir una diferencia entre indemnización equitativa y participación en los beneficios, aun cuando en el texto del Convenio parece ser patente, ya que procederá la participación en los beneficios en el caso de explotación o exploración de recursos naturales que se encuentren en tierras indígenas, pero en el caso de un daño causado a la comunidad en el contexto del proyecto, procederá la indemnización. A la vez, vemos que México indicó que los pueblos indígenas debían ser los beneficiarios directos de los proyectos, lo que es similar a lo propuesto por el exrelator Anaya, en el sentido de que existan empresas de pueblos indígenas que extraigan los recursos naturales ${ }^{85}$.

En relación con el contenido propiamente tal de la participación en los beneficios, Morgera entiende que la expresión de compartir o participar en los beneficios comprende una participación y no solo "un disfrute pasivo" de las ventajas, debido a que el derecho no es "unidireccional": se trata de un entendimiento común, dirigido a la construcción de consenso ${ }^{86}$.

Según señala Pasqualucci, de acuerdo a "los estándares de derecho internacional, los pueblos indígenas deben compartir los beneficios de los recursos naturales tomados de sus territorios" 87 . El mismo autor, citando el Reporte de los derechos y libertades fundamentales, esgrime que los pueblos indígenas deberían ser considerados como socios en esos proyectos, en el entendido de que han permitido esta participación en los beneficios ${ }^{88}$. Esto nos lleva a la idea de asociación, en la que,

antes de emprender o autorizar cualquier", lo cual responde a la negativa de varios países de reconocer la propiedad de los recursos naturales por parte de los pueblos indígenas.

83 El actual número 1 del artículo 15 es fruto de las observaciones específicas realizadas por los Estados y tomadas por la oficina en el Informe IV (2B) Conferencia InTERnacional del Trabajo (1989b)].

84 Se elimina la referencia a los recursos naturales de la fauna y la flora, las aguas y los hielos marinos, que se incluía en el Informe IV (2B) y queda el texto como el que conocemos hoy en día [CONFERENCIA InTERnacional DEL Trabajo (1989b)].

85 ANAYA (2013), párr. 12-17.

86 Morgera (2016), p. 363.

87 PASQUALUCCI (2009), p. 91. "Pursuant to evolving standards of international law, indigenous peoples must share in the benefits of natural resources taken from their territory". Traducción propia.

88 PASQUALUCCI (2009), p. 92. 
de acuerdo al exrelator Anaya, los pueblos indígenas juegan un rol significativo. Esta forma de asociación debe considerar el modo en que se toman las decisiones en la respectiva comunidad indígena, con el objeto de que sean justas ${ }^{89}$.

Es por lo antes explicado que consideramos que la participación en los beneficios constituye una garantía para posibilitar el ejercicio de la autodeterminación de los pueblos indígenas y el resguardo de su integridad cultural. Pues los recursos especificados en el artículo 15.2 del Convenio pertenecen al Estado por una cuestión estratégica, pero se les permite a los pueblos indígenas participar en los beneficios de dichos proyectos para garantizar el control sobre los recursos naturales, por su especial relación con ellos y con las tierras donde se encuentran.

Ahora bien, no todos están contestes en que la participación en los beneficios constituya una herramienta, o bien dote de contenido otros derechos, en orden a que la misma puede ser utilizada de forma maliciosa, solo para acceder al consentimiento de los pueblos indígenas ${ }^{90}$, toda vez que en algunos casos pareciera ser que la participación en los beneficios ha producido más perjuicios o daños que beneficios, como en algunos pueblos indígenas de Australia ${ }^{91}$.

Por ello, la participación debe cumplir con ciertas garantías mínimas para evitar el abuso contra las comunidades indígenas, bajo la premisa de que esta relación está compuesta por sujetos, en que uno de ellos se encuentra en una posición desventajosa. Es en esta línea que se constituye como esencial que la forma de compartir los beneficios sea justa y equitativa. Morgera entiende por tal que:

"La participación en los beneficios parece estar dirigida hacia construir el consenso y extenderse a una asociación entre diferentes actores. Este entendimiento de compartir los beneficios se ve reflejado en las teorías de la justicia y la equidad en el derecho internacional: el compromiso en el discurso donde ningún participante puede hacer una reclamación que automáticamente prevalezca sobre las reclamaciones hechas por otros participantes, y donde las inequidades en el resultado sustantivo del diálogo son solamente justificables si ellos proveen de ventajas a todos los participantes"92.

89 Wynberg et al. (2009), pp. 233, 234 y 235.

90 Morgera (2016b), p. 36.

91 Altman (2009), p. 302.

92 Morgera (2015), p. 810, “(...) benefit-sharing appears geared towards building consensus and laying the foundation for a partnership among different actors. This understanding of sharing also relates to theories on fairness and equity in international law: namely, as the commitment to engage in a discourse where no participant can make claims that automatically prevail over the claims made by other participants, and where 
Según De Jonge, no existe claridad en lo que significa "justo” y "equitativo" en relación con la participación en los beneficios o compartir los beneficios en el derecho internacional de la biodiversidad ${ }^{93}$.

Las garantías mínimas que debe reunir la participación en los beneficios se relacionan con sus formas de satisfacción, puesto que el proceso debe estructurarse en una relación de igualdad que permita la discusión y la igualdad de condiciones en la negociación. Cuando dicha forma de satisfacción se refiera a acuerdos entre empresas y pueblos indígenas, las empresas deberán dar cumplimiento a los principios rectores de empresas y derechos humanos, y otras directrices o normas no imperativas.

Ahora bien, respecto de los requisitos que los acuerdos deben cumplir y la naturaleza de los beneficios que pueden conceder para satisfacer realmente el derecho a la participación en los beneficios, serán analizadas en un artículo posterior.

\section{iii. Naturaleza de los beneficios}

La naturaleza de los beneficios puede ser variada, ya que pueden incluir beneficios en dinero o no monetarios ${ }^{94}$. Respecto de este tema, Anaya ha afirmado que:

"Los pueblos indígenas deberían percibir beneficios financieros directos -más allá de los beneficios incidentales, como los puestos de trabajo o la caridad de la empresadebido a la compensación que les corresponde por permitir el acceso a sus territorios y por los efectos adversos del proyecto que han aceptado, así como por el significativo capital social que aportan en el marco del conjunto de las circunstancias históricas y contemporáneas" 95 .

Asimismo, Anaya ha expresado que las indicadas pueden constituir modos de tomar ventaja en el proyecto que se realiza en su territorio; sin embargo, otra modalidad posible puede ser tomar parte en la gestión de los proyectos de extracción, además de todo control regulatorio que ejerzan, de acuerdo con su derecho a la libre determinación ${ }^{96}$.

inequalities in the substantive outcome of the discourse are only justifiable if they provide advantages to all participants". Traducción propia.

93 De Jonge (2011), p. 128.

94 Schroeder (2007), p. 205.

95 ANAYa (2013), párr. 76.

96 AnAYa (2013), párr. 76. 
En este sentido, Anaya afirma que existe "un patrón de acuerdos en algunas partes del mundo por los que se garantiza a los pueblos indígenas un porcentaje de las ganancias procedentes de la operación de extracción u otros ingresos, y se les proporcionan medios de participación en algunas decisiones de gestión. En algunos casos, el pueblo indígena obtiene una participación minoritaria en la operación de extracción, y por ese medio es capaz de participar en las decisiones de gestión y en las ganancias del proyecto"97.

\section{iv. La participación en los beneficios es distinta a la indemnización}

Desde la perspectiva del derecho patrimonial en general, el concepto de indemnización constituye una de las tantas formas de reparación. En el derecho internacional en especial, el objetivo de ella se traduce en una rectificación del perjuicio sufrido por la víctima o, en otras palabras, rectificar el daño hecho a la víctima, o censurar la injusticia ${ }^{98}$.

Así las cosas, la reparación debe dar una respuesta "al sentir, necesidades y proceso de las víctimas, además de a las características de las violaciones o los aspectos jurídicos. Estas pueden matizar el valor atribuido a medidas concretas, como una medida simbólica, o una reparación económica; pero también tienen una dimensión más global que atraviesa los valores en que se basan las distintas medidas"99.

Si bien la participación en los beneficios ha sido calificada como una forma de compensación ${ }^{100}$, creemos que aquello no es correcto. Esta forma de comprenderlo proviene, a nuestro juicio, de las sentencias de la Corte IDH sobre el tema, en las cuales se ha expresado que los "beneficios compartidos" surgen a partir del artículo 21.2 de la $\mathrm{CADH}$, a lo que ya hemos hecho referencia. Sin perjuicio de ello, es menester recalcar que, en caso de una vulneración a los derechos de los pueblos indígenas, la indemnización es procedente. En cambio, la participación en los beneficios tiene un fundamento diferente; supone un consenso, no un daño.

Por lo tanto, entender que la participación en los beneficios es distinta a la compensación, reafirma el contenido y fundamento al que ya hemos pasado re-

\footnotetext{
97 ANAYA (2013), párr. 77.

98 Lenzerini (2009), p. 13.

99 Martin (2013), p. 334

100 Morgera (2016b), p. 37.
} 
vista, en el entendido de que la participación en los beneficios es un componente inherente de los derechos humanos conectados con los recursos naturales ${ }^{101}$.

Ahora bien, la principal forma de satisfacción del derecho a compartir los beneficios, en la práctica, es el acuerdo entre la comunidad indígena y las empresas, o bien el Estado. Estas formas de satisfacción son diversas a las formas de implementación, puesto que por estas últimas entendemos la forma en que se entregan los beneficios; por ejemplo, a través de una fundación.

\section{v. Formas de satisfacción}

El derecho a compartir beneficios puede ser satisfecho de diversas formas, ya sea entre el Estado y los pueblos indígenas, como por ejemplo al realizar pagos por el Estado de forma directa, o la constitución de fideicomisos por el gobierno $^{102}$, o bien entre empresas y pueblos indígenas mediante acuerdos en los cuales se pactan beneficios. Respecto a estos últimos, analizaremos brevemente el marco normativo internacional en virtud del cual deben llevarse a cabo que se ha presentado en la práctica en el derecho comparado. De estos existen ejemplos especialmente en Canadá y Australia ${ }^{103}$, que no han estado exentos de críticas ${ }^{104}$, e incluso hay ejemplos en Chile ${ }^{105}$.

En Chile, solo a modo ejemplar, han existido convenciones entre las empresas y las comunidades indígenas, como es el caso del Convenio de cooperación, sustentabilidad y beneficio mutuo entre el Consejo de Pueblos Atacameños, Comunidad indígena atacameña de Río Grande y otras, y Rockwood Litio Ltda. ${ }^{106}$, en

101 Morgera (2016b), p. 39

102 Morgera (2016), p. 366.

103 Altman (2009), p. 293.

104 AYLWIN (2013), pp. 82, 83 y 85.

105 Fuente: La Tercera. Radiografía: cómo negocian hoy los pueblos originarios con las empresas, 27 de noviembre de 2016. Disponible en: http://www2.latercera.com/noticia/radiografia-negocian-hoy-los-pueblosoriginarios-las-empresas/ [1 de mayo de 2018].

106 Convenio otorgado el día 21 de febrero de 2016 ante el notario público José Miguel Sepúlveda García, El Loa, Calama. En la cláusula sexta del referido convenio se establece la participación en los beneficios para el Consejo de los Pueblos Atacameños, citando una recomendación de la Comisión Nacional para el Litio. Actualmente, se encuentra en tramitación un recurso de protección (C-10301-2018) impetrado por diversos miembros de comunidades indígenas del norte de Chile en la Corte Suprema referente a un caso en que unas modificaciones de acuerdos celebradas entre la Corfo y SQM se realizaron sin consulta previa, y en la cláusula 16 se establecieron beneficios para comunidades de esa zona, sin previa consulta ni consentimiento. Al menos debió haber existido la primera, para haber respetado el artículo 15.2 del Convenio, norma absolutamente 
donde no ha existido la participación del Estado chileno, como un ente relevante que resguarde los intereses de las comunidades, lo que puede ser una desventaja, puesto que es el Estado el primer obligado a efectivizar el derecho en estudio. En este entendido, en caso de que el Estado no sea partícipe, la empresa debiera asegurarse que la comunidad indígena se encuentra debida y técnicamente asesorada, cumpliendo con la debida diligencia que exigen los estándares de derechos humanos y empresas.

Lo anterior es relevante, puesto que quien resulta obligado por el Convenio No 169 , y por lo tanto, quien tiene el deber de respetar y garantizar el derecho a la participación de los beneficios, es el Estado respectivo, y no las empresas o instituciones privadas a las cuales se les ha concedido la autorización para efectuar los proyectos de inversión. Es por esto que en el procedimiento de celebración de acuerdo entre una empresa y los pueblos indígenas, el Estado debe tomar un rol de garante de sus derechos, evitando que los beneficios sean utilizados como presiones y asegurándose de que los acuerdos celebrados entre empresas y comunidades sean equitativos ${ }^{107}$.

Ahora bien, las empresas que operan en el territorio determinado de un Estado no deben solo respetar la ley ${ }^{108}$, sino que también deben actuar cumpliendo el marco normativo internacional representado por los Principios Rectores de Empresas y Derechos Humanos de la Organización de las Naciones Unidas, actuando con la debida diligencia exigida.

Sin embargo, estos principios rectores no son los únicos, puesto que también existen otros estándares sectoriales que es necesario mencionar, que se aplican a actividades extractivas, como son: la ICMM 2013 y la IPIECA 2012. También encontramos la norma de desempeño No $7^{109}$ de la Corporación Financiera Internacional.

Respecto a los Principios Rectores de Empresas y Derechos Humanos, creemos que las directrices fundamentales relacionadas al derecho a la participación en los

posible de ejecutar en el derecho chileno, según se estableció en el Amicus Curiae presentado por el Centro de Derechos Humanos de la Universidad Diego Portales [Carmona y Schönsteiner (2018), p. 10].

107 ANAYA (2013), párr. 24 y 62.

108 Barros y SCHÖNSTEINER (2014), p. 229.

109 Agradezco el conocimiento de estas fuentes al profesor Sebastián Donoso, por haber asistido al taller "Acuerdos entre empresas y pueblos indígenas" (noviembre, 2017). Empresas y pueblos indígenas: el nuevo escenario que plantea el Convenio No 19, p. 12, Centro de Políticas Públicas. 
beneficios son los principios $11^{110}, 12^{111}, 15^{112}$ y $18^{113}$. Dichos principios tienen por fin que las empresas den pleno respeto a los derechos humanos y que no solo exista una actitud reactiva frente a la vulneración de estos, sino que se actúe con la debida diligencia, entendiendo por esta un sistema que tenga por objeto evitar los impactos de su giro, manejando y gestionando los riesgos, y desarrollando relaciones de confianza con las comunidades locales que se encuentren cercanas a donde operan, o bien a quienes pueden afectar con sus actividades. Lo que se busca es que se genere una "cultura de cumplimiento" dentro de la organización empresarial, también entendido como la existencia de un sistema de cumplimiento normativo de derechos humanos.

El Consejo Internacional de Minería y Metales ha aprobado directrices respecto a las relaciones que deben tener sus miembros con los pueblos indígenas, y cuyos objetivos son principalmente: "respetar los derechos, intereses y las especiales conexiones entre sus tierras y aguas y las perspectivas de los pueblos indígenas, cuando los proyectos mineros están situados en tierras que tradicionalmente ocupan, o que están bajo la costumbre indígena; adoptar y aplicar un proceso de consulta que asegure los usos y costumbres de los pueblos indígenas, y que asegure la participación de los pueblos indígenas en la forma de llegar a la decisión o al acuerdo, basado en la buena fe en la negociación, y trabajar para lograr

110 "Las empresas deben respetar los derechos humanos. Eso significa que deben abstenerse de infringir los derechos humanos de terceros y hacer frente a las consecuencias negativas sobre los derechos humanos en las que tengan alguna participación".

111 La responsabilidad de las empresas de respetar los derechos humanos se refiere a los derechos humanos internacionalmente reconocidos, que abarcan, como mínimo, los derechos enunciados en la Carta Internacional de Derechos Humanos y los principios relativos a los derechos fundamentales establecidos en la Declaración de la Organización Internacional del Trabajo relativa a los principios y derechos fundamentales en el trabajo.

112 Para cumplir con su responsabilidad de respetar los derechos humanos, las empresas deben contar con políticas y procedimientos apropiados en función de su tamaño y circunstancias, a saber: a) un compromiso político de asumir su responsabilidad de respetar los derechos humanos; b) un proceso de diligencia debida en materia de derechos humanos para identificar, prevenir, mitigar y rendir cuentas de cómo abordan su impacto sobre los derechos humanos; c) unos procesos que permitan reparar todas las consecuencias negativas sobre los derechos humanos que hayan provocado o contribuido a provocar.

113 A fin de calibrar los riesgos en materia de derechos humanos, las empresas deben identificar y evaluar las consecuencias negativas reales o potenciales sobre los derechos humanos en las que puedan verse implicadas ya sea a través de sus propias actividades o como resultado de sus relaciones comerciales. Este proceso debe: a) recurrir a expertos en derechos humanos internos y/o independientes; b) incluir consultas sustantivas con los grupos potencialmente afectados y otras partes interesadas, en función del tamaño de la empresa y de la naturaleza y el contexto de la operación. 
el consentimiento de los pueblos indígenas"114. Según Barros y Schönsteiner, estas directrices se encuentran bajo los estándares internacionales incluidos en el Convenio No $169^{115}$.

De acuerdo al contexto, usos y buenas prácticas de la Asociación Internacional de la Industria del Petróleo para la Conservación Ambiental (2012), los miembros de dicha asociación deben negociar de buena fe con el objetivo de lograr acuerdos, buscando el consentimiento ${ }^{116}$.

Respecto a la norma de desempeño No 7 de la Corporación Financiera Internacional, en su párrafo 2 establece que "Los proyectos del sector privado pueden crear oportunidades para que los Pueblos Indígenas participen y se beneficien de las actividades vinculadas con dichos proyectos, que puedan ayudarlos a lograr sus aspiraciones de desarrollo económico y social. Además, los Pueblos Indígenas pueden desempeñar un papel en el desarrollo sostenible promoviendo y dirigiendo actividades y empresas como socios en el desarrollo. Los Gobiernos generalmente desempeñan un papel fundamental en el manejo de las cuestiones relacionadas con los Pueblos Indígenas y los clientes deben colaborar con las autoridades responsables en la gestión de los riesgos e impactos de sus actividades"117. En esta norma se reconoce que los pueblos indígenas pueden participar en los beneficios con un rol de asociación en el desarrollo del proyecto. Esto último refuerza nuestra idea de lo que entendemos y desarrollamos como participación en los beneficios anteriormente. Adicionalmente, pone el énfasis en el rol que el Estado debe tener al momento de enfrentar las relaciones con los pueblos indígenas.

Entre los objetivos de esta norma que nos interesan para este artículo se encuentran: i) promover beneficios y oportunidades de desarrollo sostenible para estas comunidades de una manera apropiada a sus culturas, y ii) asegurar el consentimiento previo, libre e informado de las comunidades de pueblos indígenas afectadas en el diseño, la ejecución y los resultados esperados del proyecto cuando estén presentes las circunstancias especiales descriptas en esta Norma de Desempeño ${ }^{118}$.

Respecto de la participación en los beneficios, en su párrafo 13 se establece que diversos factores (la naturaleza del proyecto, el contexto del proyecto y la vulnerabi-

\footnotetext{
114 International Council of Mining and Metals (2013), p. 3.

115 Barros y SChÖnSteiner (2014), p. 232.

116 International Petroleum Industry Environmental Conservation Association (2012), p. 15.

117 International Finance Corporation (2010), p. 273.

118 International Finance Corporation (2010), p. 273.
} 
lidad de los pueblos indígenas afectados) determinarán los beneficios de los pueblos indígenas en relación con el proyecto. Así, "las oportunidades identificadas deben considerar las metas y las preferencias de los Pueblos Indígenas, entre ellos mejorar su nivel y sus medios de vida de una manera culturalmente adecuada, y fomentar la sostenibilidad a largo plazo de los recursos naturales de los que dependen"119.

La IFC es una organización que otorga financiamiento para proyectos en países en desarrollo, entre otras funciones, por lo que los lineamientos establecidos en la norma de desempeño son esenciales para posibilitar y consolidar relaciones de confianza entre las empresas y los pueblos indígenas.

Respecto a los estándares internacionales analizados para las empresas, es importante destacar que el estándar general se encuentra constituido por los principios rectores para las empresas y derechos humanos, siendo los otros más bien sectoriales, dependiendo de la actividad extractiva a la que se dedique la empresa, aun cuando en ninguno de los dos casos constituyen normas imperativas. Es trascendental destacar el lugar esencial que tiene la debida diligencia de derechos humanos, lo que supone un compromiso de los altos directivos de cada empresa con el respeto y reparación en caso de vulneración de los derechos humanos de los pueblos indígenas.

Habiendo revisado dichas normas, podemos vislumbrar que el acuerdo aparece íntimamente incrustado en ellas, ya que todas fijan como lineamiento que la empresa debe buscar el acuerdo con la comunidad indígena, en un clima de buena fe. En este sentido, a partir de esta forma de satisfacción es que el consentimiento previo, libre e informado juega un rol primordial. En este contexto, debemos entender que el acuerdo es distinto a las formas de implementación, que son los modos por los cuales se entregan los beneficios, pero aquello supone un acuerdo para el acceso a los recursos para la realización del proyecto de inversión.

\section{Derecho a participar en los beneficios y el} CONSENTIMIENTO LIBRE, INFORMADO Y PREVIO

\section{a) Consentimiento libre, previo e informado}

Schroeder y Dutfield afirman que el consentimiento previo e informado nació en la práctica médica ${ }^{120}$. Es decir, originalmente se trataba de un concepto

119 International Finance Corporation (2010), p. 274.

120 Dutfield (2009), p. 58. 
que se aplicaba a una relación entre individuos ${ }^{121}$. Con el pasar del tiempo, este apareció en el $\mathrm{CBD}^{122}$.

Distinto es lo que sugieren Hanna y Vanclay: este concepto surgió en la mitad de la década de los $80^{123}$. Según estos autores, citando a Esteves y Vanclay, el consentimiento libre, previo e informado, por lo menos respecto "a su formal y más general utilización" ${ }^{124}$, debe analizarse en relación con cada cualidad que califica al consentimiento ${ }^{125}$. En este sentido:

"Libre significa que no debe existir coacción, intimidación o manipulación por las compañias o gobiernos, y si una comunidad dice 'no' no debe haber represalias. Previo, significa que el consentimiento debería ser buscado y recibido antes de comenzar cualquier actividad en la tierra de la comunidad y que se ha dado suficiente tiempo para las adecuadas consideraciones de las comunidad afectadas. Informado, tiene que ver con un completo conocimiento o revelación de por los desarrolladores del proyecto de sus planes en un lenguaje aceptable para las comunidades afectadas y que cada comunidad tenga suficiente información para tener un razonable entendimiento de lo que esos planes probablemente significarán para ellos, incluyendo los impactos sociales que ellos experimentarán"126.

Siguiendo a los mismos autores, para completar el concepto, consentimiento significa que "las comunidades tengan una decisión real: que ellos puedan decir sí, si el proyecto otorga beneficios y oportunidades de desarrollo para ellos, o ellos puedan decir no si ellos no están satisfechos con el trato, y que exista un mecanismo factible para entender que se trata del consentimiento de la comunidad como un todo y no solo de un grupo dentro de la comunidad" 127.

\footnotetext{
121 Dutfield (2009), p. 59.

122 Dutfield (2009), p. 59.

123 Hanna y Vanclay (2013), p. 150.

124 Hanna y Vanclay (2013), p. 150.

125 Hanna y Vanclay (2013), p. 150.
}

126 Hanna y Vanclay (2013), p. 150. "Free, meaning that there must be no coercion, intimidation or manipulation by companies or governments, and that should a community say 'no' there must be no retaliation. Prior, meaning that consent should be sought and received before any activity on community land is commenced and that sufficient time is provided for adequate consideration by any affected communities. Informed, meaning that there is full disclosure by project developers of their plans in the language acceptable to the affected communities, and that each community has enough information to have a reasonable understanding of what those plans will likely mean for them, including of the social impacts they will experience". Traducción propia.

127 Hanna y Vanclay (2013), p. 150. "Consent meaning that communities have a real choice, that they can say yes if there is a good flow of benefits and development opportunities to them, or they can say no if they are 
Esta idea es distinta a la consulta, puesto que esta es un estándar más bajo ${ }^{128}$, debido a que ella no supone necesariamente el acuerdo de la comunidad indígena con el proyecto. La consulta debiera constituir una etapa previa al acuerdo, puesto que esta debe tener por finalidad alcanzar el consentimiento, lo cual no significa o trae simultáneamente aparejado que se llegue necesariamente a un acuerdo ${ }^{129}$.

Existen Estados que han consagrado el consentimiento previo, libre e informado en su legislación, como es el caso de Filipinas y Australia ${ }^{130}$. En el primer caso, al parecer esto ha producido bastantes problemas y no ha bastado su consagración ${ }^{131}$. Esto reafirma lo que Dutfield ha expresado en cuanto a que el concepto en estudio es muy difícil de llevar a la práctica ${ }^{132}$.

\section{b) ¿Cuál es la relación que existe entre el consentimiento libre, previo e informado y la participación en los beneficios?}

Creemos que la relación que existe entre ambos conceptos es que su unión permite o posibilita un proceso de diálogo que sustenta no solo la protección de los derechos de los pueblos indígenas, sino también su ejercicio efectivo ${ }^{133}$. Puesto que el CPLI hace posible el acceso a la utilización de los recursos naturales por parte de la empresa o el Estado, acordando los beneficios o ganancias que puede generar el proyecto, en un contexto en que se negocia con anterioridad al diseño del proyecto, no existen presiones y ambas partes cuentan con la misma información. Es decir, se cumple con la debida diligencia en materia de derechos humanos.

Es por esto que incluso "la ausencia de compartir los beneficios podría proveer de legítimos motivos para las comunidades para retener el consentimiento en determinadas circunstancias" 134 , en el entendido de que la participación en los beneficios no solo debe ser ofertada como un modo de intercambiar el respeto de

\footnotetext{
not satisfied with the deal, and that there is a workable mechanism for determining whether there is wide spread consent in the community as a whole and not just a small elite group within the community". Traducción propia.

128 Agullar (2007), p. 569.

129 Meza (2013), p. 413.

130 Hanna y Vanclay (2013), p. 150.

131 Cordillera y Cordillera (2009), p. 272.

132 DutField (2009), p. 66.

133 Morgera (2016b), p. 32.

134 Morgera (2016b), p. 35, “(...) lack of fair and equitable benefit-sharing can provide legitimate grounds for communities to with hold or withdraw consent under certain circumstances".
} 
los derechos humanos por una cantidad de dinero'135: en esta relación debe estar presente la idea de asociación a la que ya hemos hecho referencia.

Según las directrices voluntarias Mootz Kuxtal ${ }^{136}$, acordadas por la Conferencia de las Partes, en sus principios generales en relación con la utilización del conocimiento tradicional, el CPLI debe ser un "proceso continuo de establecimiento de acuerdos mutuamente beneficiosos entre usuarios y titulares de conocimientos tradicionales de los pueblos indígenas y las comunidades locales, con el fin de fomentar confianza, buenas relaciones, comprensión mutua, espacios interculturales e intercambios de conocimientos y promover la creación de nuevos conocimientos y la reconciliación, e incluye la participación plena y efectiva de los pueblos indígenas y las comunidades locales, teniendo en cuenta la legislación nacional y las leyes consuetudinarias, los protocolos comunitarios y las prácticas de los pueblos indígenas y las comunidades locales, y debe respaldar y ser parte integral del desarrollo de una relación entre los usuarios y los proveedores de los conocimientos tradicionales" 137 .

Extrapolando lo establecido en el párrafo anterior para el derecho en estudio, es que CPLI debe tratarse de un proceso de diálogo en que ambas partes se beneficien en la negociación, posibilitando la participación de los pueblos indígenas en el contexto de una asociación.

Ahora bien, especialmente respecto de los grandes proyectos de extracción, el consentimiento es esencial, y ello implica la participación en los beneficios ${ }^{138}$. Es decir, existe un vínculo indisoluble, como hemos establecido, entre el consentimiento previo, libre e informado y la participación en los beneficios en razón de su fundamento, con pleno respeto a sus derechos territoriales y a los recursos naturales.

\section{CONCLUSIONES}

1. El derecho a participar en los beneficios se encuentra consagrado en diversos textos internacionales, como el Convenio de Diversidad Biológica y el Convenio No 169 de la OIT. Al alero del primero, el derecho en estudio ha tenido un

135 Morgera (2016b), p. 36.

136 Conferencia de las Partes (2016), párr. 8.

137 DEC/XIII/18: Conferencia de las Partes, de 17 de diciembre de 2016.

138 STAVEnhagen (2008), p. 70. 
desarrollo más fructífero en relación con los recursos genéticos y la conservación de la biodiversidad; a diferencia de lo que ocurre en el segundo, en que existe un reconocimiento en su artículo 15.2, pero de forma brevísima.

2. Para comprender a cabalidad el derecho a participar en los beneficios en proyectos de extracción o exploración de recursos naturales, es necesario delinear diversos elementos que constituyen presupuestos al derecho a participar en los beneficios: el derecho a la tierra, a los recursos naturales, a la consulta; esta última diversa al derecho al consentimiento previo, libre e informado.

3. Su fundamento radica primordialmente en el control de los recursos naturales, que deriva de su derecho a la libre determinación y diversos factores, como son la identidad indígena, la mantención de su subsistencia e integridad cultural.

4. El contenido de la participación en los beneficios consiste en una "asociación”, en que ambas partes puedan negociar en igualdad de condiciones los beneficios a reportar y la forma de repartirlos. Es decir, compartir los beneficios tiene como base la idea de un diálogo continuo entre ambas partes.

5. Respecto a las formas de satisfacción de este derecho, estas se encuentran íntimamente ligadas al acuerdo, el que se lleva a cabo a través de la garantía del consentimiento previo, libre e informado, en el cual cada palabra es esencial para determinar su concepto. En este contexto, juegan un rol fundamental las directrices no imperativas respecto al respecto de los derechos humanos de los pueblos indígenas, por parte de las empresas.

6. Es posible sostener que existe una relación indisoluble entre el consentimiento previo, libre e informado y la participación en los beneficios en razón de su fundamento, con pleno respeto a los derechos territoriales y a los recursos naturales.

\section{BIBLIOGRAFÍA CITADA}

Aguilar, Gonzalo (2007): Dinámica internacional de la cuestión indígena (Santiago, Librotecnia).

Aguilar, Vladimir (2017). "Extractivismos en tiempos de fragmentación de territorios indígenas", en Territorios comunes, ecología y ecologismos en Venezuela, [fecha de consulta: 12 de diciembre de 2018]. [Disponible en: https://www. ecopoliticavenezuela.org/wp-content/uploads/2018/01/TerritoriosComunesN1.pdf].

Aguilar, Gonzalo, y Alfaro, Jennifer (2015): "Los recursos naturales de los pueblos indígenas y las empresas: Estándares interamericanos y jurisprudencia chilena”, en Anuario de Derechos Humanos, (año 10, No 11), pp. 183-193. 
Almut-Schilling y Flemmer (2013). "El derecho a la consulta previa: normas jurídicas, prácticas y conflictos en América Latina”, [fecha de consulta: 2 de mayo de 2018]. [Disponible en: https://www.giga-hamburg.de/sites/default/ files/md_pdf/1303_destradi_konferenzbericht_es.pdf].

Altman, Jon (2009): "Benefit Sharing is No Solution to Development: Experiences from Mining on Aboriginal Land in Australia", en WynBERG, Rachel; Schroeder, Doris; Chennells, Roger, Indigenous Peoples, Consent and Benefit Sharing (Preston, Springer Netherlands), pp. 285-302.

AnaYA, James (2013). "Informe del relator especial sobre los derechos de los pueblos indígenas. Las industrias extractivas y los pueblos indígenas”, [fecha de consulta: 16 de junio de 2018]. [Disponible en: http://undocs.org/sp/A/ $\mathrm{HRC} / 24 / 41]$.

Aylwin, José (2013): "Mercados y derechos globales: Implicancias para los pueblos indígenas de América Latina y Canadá”, en Revista de Derecho (año 2, volumen 26).

Barros, Alonso, y SchönsteIner, Judith (2014): "Diligencia debida: proyectos de inversión, propiedad sobre los recursos naturales y consulta libre, previa e informada a los pueblos y comunidades indígenas concernidos", en Centro de Derechos Humanos, Informe Anual de Derechos Humanos 2014 (Santiago, Editorial UDP), pp. 203-244.

Bello, Álvaro (2011) "Espacio y territorio en perspectiva antropológica. El caso de los purhépechas de Nurío y Michiocán en México”, en CUHSO, pp. 40-61. Bello, Álvaro (2004): “Territorio, cultura y acción colectiva indígena: Algunas reflexiones e interpretaciones", en Aylwin Oyarzún, José (Editor), Derechos humanos y pueblos indigenas. Tendencias internacionales y el contexto chileno (Temuco, Iwgia, Walir, y el Instituto de Estudios Indígenas - Universidad de la Frontera).

CABrera, María Victoria (2017): The requirement of consultation with Indigenous Peoples in the ILO (Boston, Bill Nilhoff).

CARMOna, Cristóbal (2015): “¿Deben ser consultadas las concesiones de exploración de energía geotérmica? Susceptibilidad de afectación y territorio", en Derechos indígenas desde un enfoque multidisciplinario: Una mirada a los conflictos de la zona centro sur andina. Actas del Primer Congreso Internacional de Derecho Indígena, pp. 63-78, [fecha de consulta: 21 de octubre de 2010]. [Disponible en: https://udp.academia.edu/Crist $\%$ C3\%B3balCarmonaCaldera]. 
Carmona, Cristóbal, y Schönsteiner, Judith (2018): Amicus curiae del Centro de Derechos Humanos de la Universidad Diego Portales en el Caso "Asociación indígena Consejo de Pueblos Atacameños/SQM Potasio S.A.”, [fecha de consulta: 21 de octubre de 2010]. [Disponible en: http://www.derechoshumanos. udp.cl/derechoshumanos/index.php/publicaciones?layout=edit\&id=188].

CAstillo et al. (2009): "The Law is not Enough: Protecting Indigenous Peoplès Rights Against Mining Interests in the Philippines", en WynberG, Rachel; Schroeder, Doris; Chenells, Roger, Indigenous Peoples, Consent and Benefit Sharing (Preston, Springer Netherlands), pp. 271-284.

Comisión Interamericana de Derechos Humanos, Derechos de los pueblos indígenas y tribales sobre sus tierras ancestrales y recursos naturales. Normas y jurisprudencia del Sistema Interamericano de Derechos Humanos (2009), [fecha de consulta: 21 de octubre de 2010]. [Disponible en: https://www.oas. org/es/cidh/indigenas/docs/pdf/tierras-ancestrales.esp.pdf].

Conferencia de las Partes, DEC/XIII/18, de 17 de diciembre de 2016.

Conferencia Internacional del Trabajo (1988a), Informe VI (1). Revisión parcial del Convenio sobre poblaciones indígenas y tribuales, 1957, núm. 107. Conferencia Internacional del Trabajo (1988b), Informe IV (1), Revisión parcial del Convenio sobre poblaciones indígenas y tribuales, 1957, núm. 107. Conferencia Internacional del Trabajo (1989a) lnforme IV (2 A), Revisión parcial del Convenio sobre poblaciones indígenas y tribuales, 1957, No 107. Conferencia Internacional del Trabajo (1989b) Informe IV (2 B), Revisión parcial del Convenio sobre poblaciones indígenas y tribuales, 1957, No 107. De Jonge, Bram (2011): "What is fair and equitable benefit-sharing?", en Journal of Agricultural and Environmental Ethics (Año 24, No 2), pp 127-146.

DutField, Graham (2009): "Protecting the rights of indigenous peoples: can prior informed consent help?", en WynberG, Rachel; Schroeder, Doris; Chennells, Roger, Indigenous Peoples, Consent and Benefit Sharing (Preston, Springer Netherlands), pp. 53-67.

Del Carpio, Columba (2012): Pluralismo jurídico, derecho humano a la identidad cultural y globalización, [fecha de consulta: 12 de diciembre de 2018] [Disponible en: https://hera.ugr.es/tesisugr/20369335.pdf].

FAÚNDES, Juan Jorge (2013): "La jurisprudencia, su impacto y debates en torno a la aplicación del Convenio No 169 de la OIT y el deber de consulta”, en Revista de Derecho Universidad de Concepción, (233-234, 81), pp. 195-230. 
GuDYNAS, Eduardo (2011): "El nuevo extractivismo progresista en América del Sur". Tesis sobre un viejo problema bajo nuevas expresiones, [fecha de consulta: 12 de diciembre de 2018]. [Disponible en: http://www.gudynas.com/ publicaciones/capitulos/GudynasExtractivismoTesisColonialismo11.pdf].

Hanna, Phillippe, y Vanclay, Frank (2013): "Human rights, Indigenous peoples and the concept of Free, Prior and Informed Consent", [fecha de consulta: 2 de mayo]. [Disponible en: https://doi.org/10.1080/14615517.2013.780373].

Huaco, Marco (2015): “Los trabajos preparatorios del Convenio No 169 sobre Pueblos Indígenas y Tribales en Países Independientes", [fecha de consulta: 2 de mayo]. [Disponible en: http://www.corteidh.or.cr/tablas/31577.pdf].

International Finance Corporation (2010): "Norma de desempeño No 7", [fecha de consulta: 5 de mayo de 2018]. [Disponible en:https://www.ifc.org/ wps/wcm/connect/a9de4b80498009a0a784f7336b93d75f/Phase3_PS7_Spanish_Highlights.pdf?MOD=AJPERES].

International Council in Mining and Metals (2013): "Position statement on indigenous people and mining", [fecha de consulta: 5 de mayo de 2018]. [Disponible en: https://www.icmm.com/website/publications/pdfs/commitments/2013_icmm-ps_indigenous-people.pdf].

International Petroleum Industry EnVironmental Conservation Association (2012). "Indigenous peoples and the oil and gas industry: context, issues and emerging good practice", [fecha de consulta: 16 de junio de 2018]. [Disponible en: http://www.ipieca.org/resources/good-practice/indigenous-peoplesand-the-oil-and-gas-industry-context-issues-and-emerging-good-practice/].

LENZERINI, Federico (2009): “The trail of broken dreams: The status of indigenous people in international law", en Reparations for indigenous people. International and comparative perspectives (New York, Oxford University Press) pp. 73-116. Martín, Carlos (2013): “Derecho a la reparación en los casos indígenas", en GóMEZ, Felipe, y BerraOndo, Mikel, Los derechos indígenas tras la Declaración. El desafio de la implementación (Bilbao, Publicaciones de la Universidad de Deusto), pp. 327-344.

Meza, Matías (2013): "Capítulo II. El Convenio No 169 sobre pueblos indígenas y tribales de la Organización Internacional del Trabajo”, en AyLWIN, José, Los pueblos indígenas y el derecho (Santiago, LOM), pp. 337-439.

Meza, Matías (2013): "Capítulo III. El derecho internacional de los derechos humanos y los pueblos indígenas”, en AYLWIN, José, Los pueblos indigenas y el derecho (Santiago, LOM), pp. 441-521. 
Morgera, Elisa (2015): "Fair and Equitable Benefit-Sharing at the Cross-Roads of the Human Right to Science and International Biodiversity Law", en Laws (año 4, No 4), pp. 803-831.

Morgera, Elisa (2016a): "The need for an international legal concept of fair and equitable benefit-sharing", en The European Journal of International Law (año 27, No 2), pp. 353-383.

Morgera, Elisa (2016b): "Under the radar: fair and equitable benefit-sharing and the human rights of indigenous peoples and local communities connected to natural resources", [fecha de consulta: 5 de mayo de 2018]. [Disponible en: https://bit.ly/2KQ2VIg].

Oficina del Alto Comisionado (2011). "Principios rectores sobre empresas y derechos humanos", [fecha de consulta: 16 de junio de 2018]. [Disponible en: https://www.ohchr.org/Documents/Publications/GuidingPrinciplesBusinessHR_SP.pdf].

PASQUALUCCI, Jo (2009). "International indigenous land rights: A critique of the jurisprudence of the Interamerican Court of Human Rights in light of the United Nations Declaration on the rights of Indigenous People, [fecha de consulta: 5 de mayo de 2018]. [Disponible en: https://hosted.law.wisc.edu/ wordpress/wilj/files/2012/02/pasqualucci.pdf].

"Radiografía: cómo negocian hoy los pueblos originarios con las empresas", en $\mathrm{La}$ Tercera, 27 de noviembre de 2016, [fecha de consulta: 1 de mayo de 2018]. [Disponible en: http://www2.latercera.com/noticia/radiografia-negocian-hoylos-pueblos-originarios-las-empresas/].

Schroeder, Doris (2007): "Benefit sharing: it's time for a definition”, en Global Medical Ethics (año 4, No 33), pp. 205-209.

Schroeder, Doris (2009): “Justice and Benefit sharing”, en Wynberg, Rachel; Schroeder, Doris; Chennells, Roger, Indigenous Peoples, Consent and Benefit Sharing (Preston, Springer Netherlands), pp. 11-26.

Stavenhagen, Rodolfo (2007): Los pueblos indigenas y sus derechos (D.F. México, Unesco).

Wynberg et al. (2009): "Sharing benefits: decision-making and governance", en Wynberg, Rachel; Schroeder, Doris; Chennells, Roger, Indigenous Peoples, Consent and Benefit Sharing (Preston, Springer Netherlands), pp. 231-257.

Zalaquett, José (2008): "La Declaración de Naciones Unidas sobre Derechos de los Pueblos Indígenas", en Anuario de Derechos Humanos (año 4, No 4), pp. 139-148. 


\section{NORMAS JURÍDICAS CITADAS}

Convenio No 169 de la Organización Internacional del Trabajo, de 27 de junio de 1989.

Convenio de Diversidad Biológica de las Naciones Unidas, de 5 de junio de 1992.

\section{JURISPRUDENCIA CITADA}

Caso del Pueblo Saramaka vs. Surinam (2008): Corte Interamericana de Derechos Humanos, 12 de agosto de 2008.

Caso Pueblo Kichwa de Sarayaku vs. Ecuador (2012): Corte Interamericana de Derechos Humanos, 27 de junio de 2012.

Caso Pueblos Kaliña y Lokono vs. Surinam (2015): Corte Interamericana de Derechos Humanos, 25 de noviembre de 2015.

Caso Comunidad Garifuna de Punta Piedra vs. Honduras (2015): Corte Interamericana de Derechos Humanos, 8 de octubre de 2015. 